\title{
Егорашин В.Г. \\ Факторы, обуславливающие оптимальный ход зимовки пчелиных семей и его закономерности
}

ФГБОУ ВО «Нижегородская государственная сельскохозяйственная академия» (Россия, Нижний Новгород)

doi: $10.18411 / 1 j-07-2021-17$

\section{Аннотация}

Показана роль абиотических факторов в зимовке пчёл. Рассчитаны регрессионное уравнение связи силы пчелиной семьи с динамикой суточной нагрузки на кишечник отдельных пчёл, номинальная минимальная сила пчелиной семьи способная пережить холодный период года.

Ключевые слова: пчёлы, абиотические факторы зимовки, нагрузка на кишечник зимующей пчелы.

\section{Abstract}

The role of abiotic factors in the wintering of bees is shown. The regression equation of the relationship between the strength of the bee family and the dynamics of the daily load on the intestines of individual bees, the nominal minimum strength of the bee family able to survive the cold period of the year, is calculated.

Keywords: bees, abiotic factors of wintering, load on the intestines of a wintering bee.

Семьи медоносных пчёл представляют собой сообщества экологически пластичных по своей организации насекомых. Длительные эволюционные преобразования так изменили биохимию и физиологию пчелиного организма, внешне подкрепив их полезными этологическими приобретениями, что в итоге позволило медоносным пчёлам расселиться на огромной территории и даже занять некоторым её «ультра холодным» географическим расам территории вплоть до приполярных районов.

Очевидно, что в столь экстремальных для ведения пчеловодства районах с продолжительной зимовкой и безоблётным периодом, сама подготовка пчелиных семей к зимовке на всех её уровнях должна осуществляться более тщательно, с учётом многих факторов, влияющих на данный процесс. В подобной обстановке сама подготовка пчелиных семей к зимовке сопряжена с прохождением насекомыми нескольких естественно-физиологических уровней (или изменений): 1. Сезонные изменения, происходящие непосредственно в самом организме отдельных пчёл, включающие биохимический, физиологический и поведенческий уровни; 2. Внутрисемейные изменения, при вхождении в режим выживания во время периода формирования зимнего клуба пчёл, за счёт эффекта синергетической иррадиации индивидуальных сезонных изменений первого уровня на уровень пчелиной семьи - как суперорганизма в целом.

Какие же экологические факторы являются критичными для зимующих пчёл? Пчеловодная практика показывает, что главная причина неблагоприятной зимовки и гибели зимующих пчел кроется в повышенной влажности воздуха. Давно замечено, что в слякотные, с оттепелями, туманами и большим количеством осадков зимы пчелы зимуют гораздо хуже, чем в сухие и морозные. Естественное увеличение потерь тепла клубом пчёл во время сырых, с влажным атмосферным воздухом, зим, приводит, образно говоря, к эффекту «раздевания» семей медоносных пчёл и понижению их энергетической эффективности.

В связи с вышеприведёнными факторами, с которыми сталкиваются семьи зимующих пчёл, не менее важно определить потенциальные способности малочисленных пчелиных семей к прохождению ими зимовки.

В данном исследовании предпринята попытка найти и проанализировать факторы и закономерности, влияющие на прохождение пчелиными семьями зимовки. 
Сделана попытка рассчитать ту минимальную номинальную величину силы пчелиной семьи, благодаря которой малочисленные семьи пчёл потенциально способны пережить зимний период.

Для этого в начале исследования: в конце августа - начале сентября были искусственно сформированы десять пчелиных семей разной силы с матками сеголетками. Первая семья была подведена к зимовке с живой массой пчёл равной около 1000 г (соответственно 10 тыс. пчёл), занимала 4 обсиженных гнездовых дадановских (435 х300 мм) рамок. Каждая последующая семья была на 500 г тяжелее (на 5 тыс. пчёл больше, а их гнездо было больше соответственно на 2 дадановские рамки).

Энергетические характеристики таких искусственно сформированных семей приведены в табл. 1.

Таблийа 1

Энергетическая характеристика сформированных семей

\begin{tabular}{|c|c|c|c|c|c|c|}
\hline $\begin{array}{c}\text { Рамки, } \\
\text { занятые } \\
\text { пчёлами, } \\
\text { шт. }\end{array}$ & $\begin{array}{c}\text { Количество } \\
\text { пчел, тыс. }\end{array}$ & $\begin{array}{c}\text { Объем } \\
\text { клуба, } \\
\mathrm{m}^{3}{ }^{3} 10^{-3}\end{array}$ & $\begin{array}{c}\text { Диаметр } \\
\text { клуба, м }\end{array}$ & $\begin{array}{c}\text { Расход } \\
\text { энергии на } \\
\text { обогрев пчел } \\
\text { W, Вт/м }\end{array}$ & $\begin{array}{c}\text { Выделение } \\
\text { тепла одной } \\
\text { пчелой, мВт }\end{array}$ & $\begin{array}{c}\text { Выделение } \\
\text { тепла семьёй, } \\
\text { Вт }\end{array}$ \\
\hline 4 & 10 & 3,28 & 0,18 & 1481 & 0,48 & 4,86 \\
\hline 6 & 15 & 4,92 & 0,21 & 1088 & 0,36 & 5,35 \\
\hline 8 & 20 & 6,56 & 0,23 & 907 & 0,30 & 5,90 \\
\hline 10 & 25 & 8,21 & 0,25 & 768 & 0,25 & 6,30 \\
\hline 12 & 30 & 9,85 & 0,26 & 710 & 0,23 & 6,99 \\
\hline 14 & 35 & 11,48 & 0,28 & 612 & 0,20 & 7,03 \\
\hline 16 & 40 & 13,12 & 0,29 & 571 & 0,19 & 7,49 \\
\hline 18 & 45 & 14,76 & 0,30 & 533 & 0,17 & 7,87 \\
\hline 20 & 50 & 16,40 & 0,31 & 499 & 0,16 & 8,18 \\
\hline 22 & 55 & 18,04 & 0,33 & 441 & 0,14 & 7,96 \\
\hline
\end{tabular}

Общеизвестно, что единственным источником энергии зимующих пчёл является мёд. Так, в 1 кг мёда содержится 3,1 кВт•ч (3100 Вт·ч). Кроме этого, при поедании одного килограмма мёда (с содержанием воды до 25\%) пчёлы в процессе его окисления, выделяют, около 0,5 л воды в атмосферу улья. Насыщенный водяными парами ульевой воздух, не будучи вовремя удалённым из улья, может провоцировать его конденсацию, разжижение и порчу мёда, а на фоне естественного в таких условиях увеличения теплопроводности - и к замерзанию зимующих пчёл. В приведённом случае неизбежно возникает обстановка «вентиляционного кризиса»: чем более интенсивно пчёлы осуществляют вентиляцию для уменьшения критичной влажности воздуха и уменьшения пчёлами клуба теплопотерь, тем более критично влажной становится ульевая атмосфера, из-за дыхания насекомых.

В подобных складывающихся условиях, для поддержания гнездового микроклимата в улье, кроме диффузии водяных паров через его стенки или накопление паров воды в пористом материале утеплителя внутри улья, наиболее радикальной мерой для пчёл может быть вынос излишней метаболической воды из своего гнезда в процессе его вентиляции. Известно, что интенсивность вентиляции улья можно оценить через кратность его воздухообмена. В итоге, чем интенсивнее вентиляция, тем больше энергии тратят пчёлы на поддержание оптимального гнездового гомеостаза.

Достаточно ли окажется количества энергии пчёлам для поддержания приемлемого уровня гнездового гомеостаза при разной мощности (силе) зимующего клуба пчёл рассмотрим ниже (см. табл. 2). 
Таблииа 2

Вещуественно-энергетическая характеристика семей

\begin{tabular}{|c|c|c|c|c|c|}
\hline $\begin{array}{c}\text { Рамки, } \\
\text { занятые } \\
\begin{array}{c}\text { пёлами, } \\
\text { шт. }\end{array}\end{array}$ & $\begin{array}{c}\text { Количество } \\
\text { пчел, тыс. }\end{array}$ & $\begin{array}{c}\text { Рнергии на } \\
\text { обогрев } \\
\text { Пчел } \\
\mathrm{W}, \mathrm{BT} / \mathrm{M}^{3}\end{array}$ & $\begin{array}{c}\text { Объем } \\
\text { клуба, } \\
\mathbf{M}^{3} 1^{-3}\end{array}$ & $\begin{array}{c}\text { Расход мёда на } \\
\text { обогрев пчёл (в } \\
1000 \text { г } \\
\text { содержится } \\
3100 \text { Вт·ч) }\end{array}$ & $\begin{array}{c}\text { Количество } \\
\text { метаболической воды (г), } \\
\text { выделенной при расходе } \\
\text { энергии на обогрев пчёл } \\
\text { за 1 сутки }\end{array}$ \\
\hline 4 & 10 & 1481 & 3,28 & 0,48 & 5,76 \\
\hline 6 & 15 & 1088 & 4,92 & 0,35 & 4,2 \\
\hline 8 & 20 & 907 & 6,56 & 0,29 & 3,48 \\
\hline 10 & 25 & 768 & 8,21 & 0,25 & 2,76 \\
\hline 12 & 30 & 710 & 9,85 & 0,23 & 2,4 \\
\hline 14 & 35 & 612 & 11,48 & 0,20 & 2,16 \\
\hline 16 & 40 & 571 & 13,12 & 0,18 & 2,04 \\
\hline 20 & 45 & 533 & 14,76 & 0,17 & 1,92 \\
\hline 22 & 50 & 499 & 16,40 & 0,16 & 1,68 \\
\hline
\end{tabular}

Здесь уместно и необходимо привести несколько объяснений. Так, известно, что содержание энергии в мёде составляет 11300 кДж/кг, для воды теплота парообразования составляет 2400 кДж/кг, таким образом, «калорийность» или энергосодержание мёда позволяет многократно испарить «бывшую в нём» воду. При расчёте данный коэффициент равен примерно 4,71. Это означает, что полученная энергия от 1 г потреблённого мёда способна испарить около 4,7 г воды. С учётом приведённых параметров изменение характеристик гигро-энергетического баланса ульевого гнезда исследуемых пчелиных семей выглядит следующим образом (см. в табл. 3).

Таблица 3

Изменение нагрузки на кишечник у зимующих пчёл семей разной силь

\begin{tabular}{|c|c|c|c|c|}
\hline $\begin{array}{l}\text { Количе- } \\
\text { ство пчел, } \\
\text { тыс. }\end{array}$ & $\begin{array}{l}\text { Расход мёда на } \\
\text { обогрев пчёл (в } \\
1000 \text { г содержится } \\
3100 \mathrm{BT}^{\prime} \text { ч) }\end{array}$ & $\begin{array}{l}\text { Количество } \\
\text { метаболической } \\
\text { воды (г), выделенной } \\
\text { при расходе энергии } \\
\text { на обогрев пчёл за } 1 \\
\text { сутки }\end{array}$ & $\begin{array}{l}\text { Расход мёда (г) на } \\
\text { испарение } \\
\text { метаболической } \\
\text { воды пё пчелиной } \\
\text { семьёй за } 1 \text { сутки }\end{array}$ & $\begin{array}{lr}\text { Каловая } & \text { нагрузка } \\
\text { на } 1 & \text { пчелу } \\
\text { (мг/сутки) } & \end{array}$ \\
\hline 10 & 0,48 & 5,76 & 1,23 & 0,171 \\
\hline 15 & 0,35 & 4,2 & 0,89 & 0,0827 \\
\hline 20 & 0,29 & 3,48 & 0,74 & 0,0515 \\
\hline 25 & 0,25 & 3,0 & 0,64 & 0,0356 \\
\hline 30 & 0,23 & 2,76 & 0,59 & 0,0273 \\
\hline 35 & 0,20 & 2,4 & 0,51 & 0,0203 \\
\hline 40 & 0,18 & 2,16 & 0,46 & 0,016 \\
\hline 45 & 0,17 & 2,04 & 0,43 & 0,013 \\
\hline 50 & 0,16 & 1,92 & 0,41 & 0,0114 \\
\hline 55 & 0,14 & 1,68 & 0,36 & 0,0091 \\
\hline
\end{tabular}

По данным табл. 3 видно, что с увеличением силы зимующих семей уменьшается нагрузка на кишечник каждой зимующей пчелы. Изменение данного показателя, апроксимированного степенной функцией с коэффициентом детерминации близким к единице, представлено на рис. 1. 


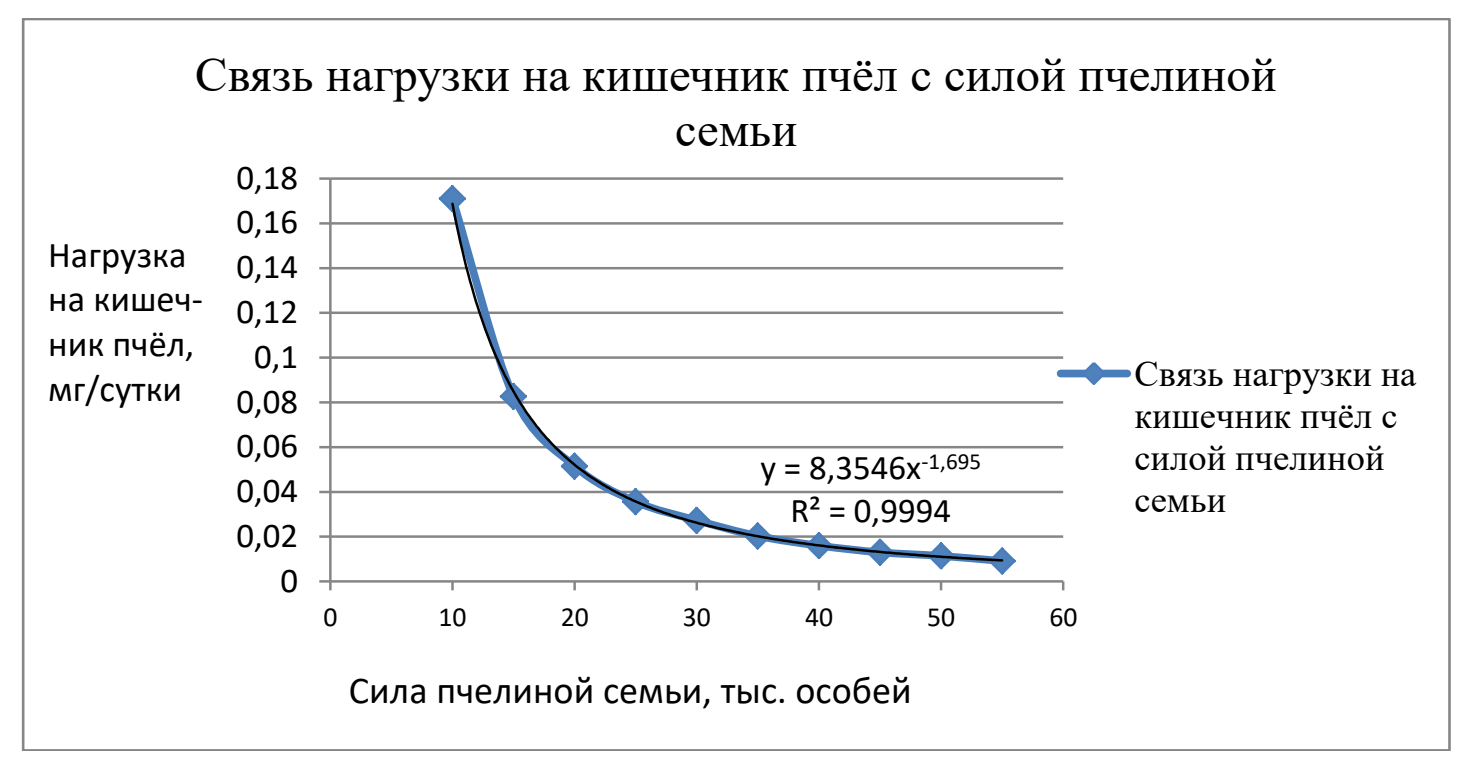

Рис. 1. Изменение нагрузки кишечника у пчёл в семьях разной сильл.

Поскольку энергетическим источником для пчёл является исключительно мёд, то потенциал зимовки пчёл упирается в конечную ёмкость их кишечника, в потенциале удерживающего до 40 - 43 мг неперавенных остатков пищи или почти половину веса своего тела [1]. При дальнейшем повышении каловой нагрузки, если пчёлы не в состоянии совершить очистительный облёт, может случиться их испражнение, самоотравление и даже гибель семьи.

По выявленной в процессе исследования закономерности влияния силы пчелиных семей на нагрузку кишечника отдельных пчёл, удалось найти минимальную силу семьи, способной пережить зимний период. Связь силы семей и нагрузки на кишечник пчёл аппроксимируются степенной функци: $\mathrm{y}=8,3546 \mathrm{x}^{-1,695}$ (где X - сила семьи, а у=усреднённая нагрузка на кишечник зимующих пчёл), Достоверность аппроксимации составила $\mathrm{R}^{2}=0,9994$.

Данное минимальное количество особей в зимующей семье пчёл по расчётам из уравнения составило 7300 - 7500. Данный показатель не претендует на сколь-нибудь большую точность, но может стать некоторым ориентиром, позволяющим более объективно оценивать возможности выживания очень слабых пчелиных семей, которое может быть предоставлено им стечением чрезвычайно благоприятных для этого условий, прежде всего влажностно-термических. Подобные благоприятные влажностно-термические условия зимующего гнезда пчёл, наряду с прочими условиями (наличием доброкачественных кормов, газового состава и пр.) переводят физиологический режим организма пчёл на экономное расходование кормовых запасов и жизненной энергии насекомых. Данное обстоятельство значительно отодвигает время вынужденного очистительного облёта для освобождения кишечника пчёл от непереваренных остатков пищи, приурочивая его к наиболее комфортным для пчёл погодным условиям, что и предопределяет более благополучную зимовку медоносных пчёл и сохранению в этот период их жизненной энергии.

\section{$* * *$}

1. Таранов Г.Ф. Корма и кормление пчёл. - 2-е изд., перераб. и доп. - М Россельхозиздат, 1986. 160 с., ил. 